\title{
Effects of water soluble extract from the dead leaves of deciduous trees on the growth control of toxic cyanobacteria like Microcystis aeruginosa
}

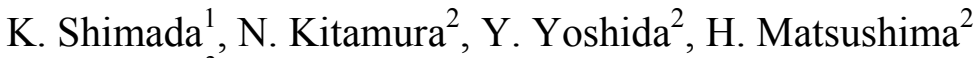 \\ \& Y. Asada ${ }^{3}$ \\ ${ }^{1}$ Civil Engineering Department, Graduate School of Science and \\ Technology, Nihon University, Japan \\ ${ }^{2}$ Civil Engineering Department, College of Science and Technology, \\ Nihon University, Japan \\ ${ }^{3}$ General Education Department, College of Science and Technology, \\ Nihon University, Japan
}

\begin{abstract}
Because of the toxic microcystin from Microcystis aeruginosa (M.a.) in eutrophicated lakes and reservoirs, effective counter measures against its excessive growth have been widely called for. Recent research on the growth control of Microcystis was conducted especially concerning the effects of straw and emergent plants. The authors have discussed that the water soluble extract (WSE) from the dead leaves of deciduous trees like cherry (Purunus Yedoensis) and maple (Acer buergerianum Miq.) bring about a clear effect on the growth control of M.a. The WSE solutions from the dead leaves of cherry and maple trees were added to an M.a. culture solution to set the initial condensed tannin loading intensity (CTLI) per unit cell at about $26 \mathrm{pg}-\mathrm{CT} / \mathrm{cell}$, and then, the daily change of the M.a. cell concentration was observed. Accordingly, the WSE addition resulted in controlling the cell concentration and its influence was clearly affected by the initial CTLI level. The condensed tannin (CT) in the WSE solution was preferentially separated to produce a CT fraction (CTF) solution by use of casein/acetone, and thus the CTF solution also caused a good growth control. The WSE fractioning treatment resulted in separating the CT substance from the WSE solution. As for the growth control tests using the
\end{abstract}


WSE and CTF solutions, the initial CTLI level was set at between 13 to 18 pg$\mathrm{CT} /$ cell, and accordingly the CT effect was confirmed in terms of the growth control similarly in both the WSE and the CTF addition cases. Therefore, the results imply that the CT extracted from the dead leaves is the major growth control factor of M.a., and thus the dead leaves of deciduous trees function as an effective growth control agent.

Keywords: water soluble extract, condensed tannin, dead leaves, growth control, Microcystis aeruginosa.

\section{Research background}

Eutrophication in inland lakes and reservoirs induces the excessive growth of phytoplankton under relatively high water temperature conditions from late spring through summer seasons. Along with the advance of this phenomenon that is called algal blooming or "Aoko" in Japanese, toxic cyanobacteria such as Microcystis and Anabaena especially grow and produce toxic substances like microcystin and anatoxin. Consequently, in the lakes where the algal blooming occurred, there were deaths of animals and fish and even incidents of human death due to lake water use in Brazil in 1996. These examples reflect the urgent need of counter measures for controlling the growth of the toxic cyanobacteria in regard to water environment preservation and water resource protection. Practical counter measures against algal blooming, include direct sediment/algal removal, copper sulfate addition, supersonic treatment [1], and electric processing [2]. These have been implemented although each process was not always technically effective, economically practical, or environmentally sustainable. Otherwise, there are some other reports on studies about the growth control of toxic cyanobacteria through the use of the natural plants like barley straw [3,4]. In respect to the growth control of Microcystis, Ridge et al. [5] reported about the effects of leaf litter, and Nakai et al. [6] examined the influence of emergent plants like Myriophyllum spicatum. In these reports, it was supposed that the polyphenol (PP) of the natural organic compounds acts as an inhibitory factor to control the growth of the toxic cyanobacteria. Polyphenol has been known to hold medicinal actions [7, 8]. Antibacterial or bactericidal action has also been reported about the effect of catechin contained in tea, which is due to condensed tannin such as catechin that has been polymerized in several molecule units [9-11]. Toda et al. [12] examined the antibacterial action of catechin to E. coli forms, and Augustin et al. [13] reported on the bactericidal action of condensed tannin.

\section{Research objectives}

The authors have conducted a series of experiments about the effects of water soluble extract (WSE) from the dead leaves of deciduous trees like cherry (Purunus Yedoensis) and maple (Acer buergerianum Miq.) on the growth control of Microcystis aeruginosa (M.a.). Consequently, the growth control was clearly observed on occasions of the WSE solution addition in comparison with the 
control in which the WSE solution was not added. The results show that condensed tannin (CT) was detected in the WSE solution and is believed to be one of the important factors affecting the growth control [14]. The major objective this research aimed at finding was whether or not the CT functions as a growth control/inhibitory factor of M.a. cells when using the WSE solution containing the CT from the dead leaves of cherry trees and the CTF solution coming from the WSE solution that has been fractioned by the use of casein/acetone. That is, the CT in the WSE solution could be preferentially separated to hold the CT substance in the solution, which is defined as the CTF solution. The remaining solution after the fractioning treatment of the WSE solution to separate the CT substance would contain no condensed tannin or less condensed tannin than the WSE solution itself or the CTF solution. This is defined as the WSE-remaining solution (WSE-R). These three solutions of WSE, CTF and WSE-R were used for experimentally evaluating the effects of the CT from the dead leaves on the growth control of toxic cyanobacteria like Microcystis aeruginosa.

\section{Experimental procedures for M.a. growth control}

\subsection{Preparation of the WSE, CTF and WSE-R solutions}

In order to prepare the WSE solution containing the CT from dead leaves, dead leaves of deciduous trees like cherry and maple were collected at several parks in metropolitan Tokyo during late autumn and early winter. The dead in-room-dried leaves were first pulverized by a food mixer at 7,000 rpm for 30 seconds, and the pulverized sample of $1.0 \mathrm{~g}$ was immersed in $100 \mathrm{~mL}$ of D.I. water under laboratory room conditions for the seven days following the pulverization. Then, the supernatant portion was filtered to prepare the WSE solution. The WSE fractioning treatment to obtain the CTF solution was based on the procedure as in the flow chart in Figure 1 [15].

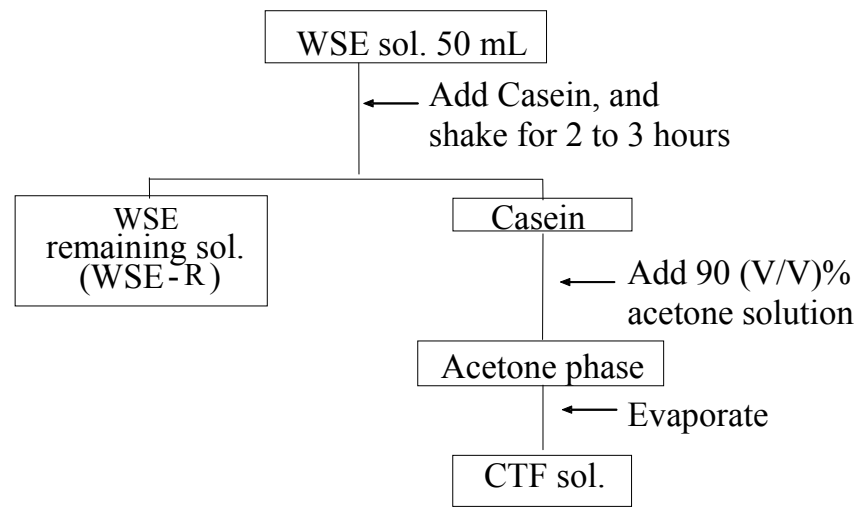

Figure 1: WSE fractioning treatment for CTF solution. 
The WSE solution of $50 \mathrm{~mL}$ was first prepared as above, into which $2 \mathrm{~g}$ of casein (Wako Pure Chemical Industries, Ltd., Japan) was added and agitated vigorously for 2 to 3 hours. Then, the casein was removed after the solution had sat for several minutes. Into the removed bulk of the casein was added a $50 \mathrm{~mL}$ 90 (v/v) \% acetone solution, and it was air-stopped with a Parafilm (Pechiney Plastic Packaging Incorporation, USA). After agitating for one night, the acetone portion was removed by a rotary evaporator. In this remaining solution the CT substance itself was preferentially separated from the original WSE solution, and this is defined as the CTF solution. Furthermore, after the WSE fractioning treatment, the remaining solution would presumably contain less or no condensed tannin than the original WSE solution or the CTF solution. This is defined as the WSE remaining solution (WSE-R). Growth control tests using the WSE-R solution resulted in observing no growth control effect because of the less or no CT substance existing.

\subsection{Condensed tannin analysis in WSE, CTF and WSE-R solutions}

In general, the $\mathrm{CT}$ reacts with a $1 \%$ ferric chloride solution to produce a dark green color for cherry WSE solution and a dark blue color for maple WSE solution. The concentration analysis on the WSE and CTF solutions was based on the vanillin-sulfuric method for condensed tannin [16] and the Folin-Denis method for polyphenol [17]. Both the CT and PP concentrations have been expressed in catechin equivalent. For the CT and PP quantitative analysis, the pure chemical of $(+)$-Catechin Hydrate was purchased from Spectrum Chemical MFG Corp., USA. The PP naturally contained CT.

\subsection{Pre-incubation of M.a.}

The Microcystis aeruginosa culture (NIES 102) for the present experiments was originally transferred from the National Institute for Environmental Studies (NIES) in Japan. Before use for the growth control tests, the M.a. culture was pre-incubated at $28 \pm 1{ }^{\circ} \mathrm{C}$ under a light intensity of 2,500 to 3,000 lux for 16 hours light and 8 hours dark condition for the seven days following the initiation of pre-incubation. For the M.a. culture pre-incubation, a M-11 culture medium solution which had been pre-autoclaved for sterilization at $121^{\circ} \mathrm{C}$ for 15 minutes was used for the growth control tests as in Table 1.

Table 1: $\quad$ Nutrients in the M-11 culture medium solution.

\begin{tabular}{lrlr}
\hline $\mathrm{NaNO}_{3}$ & $100.0 \mathrm{mg}$ & $\mathrm{Na}_{2} \mathrm{CO}_{3}$ & $20.0 \mathrm{mg}$ \\
$\mathrm{K}_{2} \mathrm{HPO}_{4}$ & $10.0 \mathrm{mg}$ & $\mathrm{FeSO}_{4} \cdot 7 \mathrm{H}_{2} \mathrm{O}$ & $1.0 \mathrm{mg}$ \\
$\mathrm{MgSO}_{4} \cdot 7 \mathrm{H}_{2} \mathrm{O}$ & $75.0 \mathrm{mg}$ & $2 \mathrm{NA}(\mathrm{EDTA} \cdot 2 \mathrm{Na})$ & $1.0 \mathrm{mg}$ \\
$\mathrm{CaCl}_{2} \cdot 2 \mathrm{H}_{2} \mathrm{O}$ & $40.0 \mathrm{mg}$ & Deionized Water & $1,000 \mathrm{~mL}$ \\
\hline & & & $\mathrm{pH}=8.0$
\end{tabular}




\subsection{Growth control tests using WSE and CTF solutions}

Procedures for the M.a. growth control tests are briefly summarized. A $150 \mathrm{~mL}$ M-11 culture medium solution that was previously sterilized as above was separated into a test bottle of $500 \mathrm{~mL}$ Erlenmeyer flask, into which a NIES 102 pre-incubated culture was added to set up the initial cell concentration at about 300,000 cells $/ \mathrm{mL}$. Then, the WSE or CTF solution that was pre-filtered through a $0.22 \mu \mathrm{m}$ membrane filter (Millipore Corporation, Japan) was added into the test bottle. The legend of the control in each figure is when neither the WSE nor the CTF solution was added into the test bottle. The growth control effect was examined on the basis of observing the daily change of cell concentration in the mixture solution of the test bottle. After the cyanobacterial colony in the mixture solution inside the test bottle was scattered by a supersonic treatment, a small amount of the mixture solution was quickly taken into a Hemacytometer Thoma Type Counting Chamber to directly measure the cell number by a microscope. The cell number measurement was conducted five to ten times for each of the five samples from the test bottle mixture solution.

\section{Results and discussions}

\subsection{CT and PP analysis on WSE solution}

Two kinds of dead leaves from cherry and maple trees were used to prepare the WSE solutions, and then the CT and PP concentrations on each WSE solution were analyzed and listed in Table 2 . The $\mathrm{CT}$ and PP concentrations are expressed in $\mathrm{mg}-\mathrm{CT} / \mathrm{mL}$ and $\mathrm{mg}-\mathrm{PP} / \mathrm{mL}$ as catechin equivalent.

Table 2: $\quad$ CT and PP analysis on WSE solution.

\begin{tabular}{lccc}
\hline & $\mathrm{CT}(\mathrm{mg}-\mathrm{CT} / \mathrm{mL})$ & $\mathrm{PP}(\mathrm{mg}-\mathrm{PP} / \mathrm{mL})$ & $\mathrm{CT} / \mathrm{PP}$ Ratio \\
\hline cherry & 0.13 & 0.54 & 0.24 \\
maple & 0.32 & 0.95 & 0.34 \\
\hline
\end{tabular}

According to Table 2, the CT extractions from the cherry and maple trees were $0.13 \mathrm{mg}-\mathrm{CT} / \mathrm{mL}$ and $0.32 \mathrm{mg}-\mathrm{CT} / \mathrm{mL}$ respectively, and the PP extractions were $0.54 \mathrm{mg}-\mathrm{PP} / \mathrm{mL}$ and $0.95 \mathrm{mg}-\mathrm{PP} / \mathrm{mL}$. As a result, the CT/PP ratios were 0.24 and 0.34 respectively for each kind of dead leaf, which means that the CT and PP extraction amounts from the maple trees were higher than those of the cherry. Although it is not clearly understood, it probably is due to the kind of deciduous trees, the sunlight intensity during the photosynthesis light reaction, or the differences in sample-collecting time or location of the dead leaves.

\subsection{CT extraction from dead leaves}

Incidentally, the extraction volume for the WSE solution preparation was actually $100 \mathrm{~mL}$ for $1 \mathrm{~g}$ of the dry dead leaves, and the total extraction per unit 
weight of the dead leaves was estimated to be $13 \mathrm{mg}-\mathrm{CT} / \mathrm{g}$ for the cherry and 32 $\mathrm{mg}-\mathrm{CT} / \mathrm{g}$ for the maple. The CT substance elutes easily into water from the dead leaves, and the amount of the CT extracted from the cherry tree after seven days immersion under room temperature was 13 to $20 \mathrm{mg}-\mathrm{CT} / \mathrm{g}$ for D.I. water and 11.9 to $14.8 \mathrm{mg}-\mathrm{CT} / \mathrm{g}$ for lake waters. As for the solvent extraction from the dead cherry leaves, the possible amount of the CT extracted by a $50 \%$ ethanol solution (ethanol:D.I. water $=1: 1 \mathrm{v} / \mathrm{v}$ ) was 18.6 to $21.9 \mathrm{mg}-\mathrm{CT} / \mathrm{g}$. When using a $50 \%$ ethanol solution, the CT extraction process was actually repeated three times, and a coloring reaction was not observed for the supernatant solution when a drop of ferric chloride solution was added. Therefore, the CT contained in the dead leaves of the cherry tree seemed to be completely removed by the $50 \%$ ethanol solution. Accordingly, the CT extraction rate by the D.I. water would be about $0.60 \sim 0.91$ (average 0.72) when compared with that of the 50\% ethanol solution, which means that the CT substance was easily extracted with a relatively high recovery rate only by immersing the dead leaves into water.

\subsection{Effects of CT on M.a. growth control}

Using the two kinds of WSE solutions from the dead cherry and maple leaves, the M.a. growth control tests were conducted and the results were plotted in Figure 2.

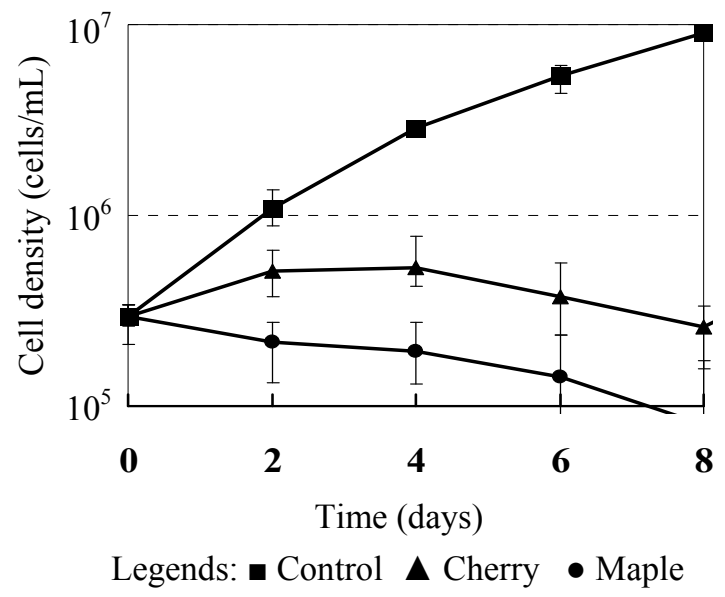

Figure 2: $\quad$ Effects of WSE solution on M.a. growth control under CTLI of 26 pg-CT/cell.

The CT was supposed to be the major growth control factor. Based on the pre-determined CT concentration in each WSE solution, the addition of the cherry WSE solution was decided to be $10 \mathrm{~mL}$, and that of the maple WSE solution was $4 \mathrm{~mL}$ because of the CT extraction difference between the two kinds of dead leaves. Accordingly, the initial CT concentration was $0.008 \mathrm{mg}$ $\mathrm{CT} / \mathrm{mL}$ in both test bottles, while the PP concentration was $0.032 \mathrm{mg}-\mathrm{PP} / \mathrm{mL}$ for 
the cherry WSE solution and $0.024 \mathrm{mg}-\mathrm{PP} / \mathrm{mL}$ for the maple WSE solution. Therefore, the CTLI per unit M.a. cell in each test bottle was initially adjusted at $26 \mathrm{pg}-\mathrm{CT} /$ cell. In this case, the initial M.a. cell concentration was arranged to be about 300,000 cells $/ \mathrm{mL}$. As in Figure 2 showing the M.a. cell concentration change in the control test bottle, the M.a. cell seemed to be growing during the first 8 days of the test period. Distinct growth control/inhibition was observed in the WSE added-test bottles. This implies that some water soluble substances like the condensed tannin were very effectively acting on the growth control of the M.a. cells. Although the CTLI was set up initially at nearly the same level for the test bottles, the effect on the growth control was a little bit higher when using the maple WSE solution than when using the cherry WSE solution. The growth control seems to have been affected by the composition and/or the amounts of the PP of the organic substances in the WSE solution.

\subsection{Effect of fractioning treatment on CT separation}

Table 3 shows the CT and PP amounts and the CT/PP ratios in the WSE and CTF solutions obtained from the dead cherry leaves. The CT and PP concentrations of Sample 1 were $0.09 \mathrm{mg}-\mathrm{CT} / \mathrm{mL}$ and $0.40 \mathrm{mg}-\mathrm{PP} / \mathrm{mL}$ for the WSE solution, and $0.05 \mathrm{mg}-\mathrm{CT} / \mathrm{mL}$ and $0.06 \mathrm{mg}-\mathrm{PP} / \mathrm{mL}$ for the CTF solution. The CT/PP ratio of Sample 1 was 0.23 for the WSE and 0.83 for the CTF respectively. This implies that the WSE fractioning treatment using casein/acetone results in an increase in the CT/PP ratio of the CTF since the fractioning treatment aims to preferentially separate the CT substance from the WSE solution to obtain the CTF solution with a higher CT/PP ratio. According to Table 3, the CT/PP ratios of the other samples ranged from 0.19 to 0.25 for the WSE solutions and from 0.29 to 0.83 for the CTF solutions. The WSE fractioning treatment by use of casein/acetone would seem to effectively but not completely separate the CT substance itself.

Table 3: $\quad$ Amounts of CT and PP in WSE and CTF solutions.

\begin{tabular}{llccc}
\hline Sample \# & Solutions & $\mathrm{CT}(\mathrm{mg}-\mathrm{CT} / \mathrm{mL}) \mathrm{PP}(\mathrm{mg}-\mathrm{PP} / \mathrm{mL})(\mathrm{CT} / \mathrm{PP})_{\mathrm{WSE}} /(\mathrm{CT} / \mathrm{PP})_{\mathrm{CTF}}$ \\
\hline Sample 1 WSE/CTF & $0.09 / 0.05$ & $0.40 / 0.06$ & $0.23 / 0.83$ \\
Sample 2 WSE/CTF & $0.12 / 0.07$ & $0.59 / 0.15$ & $0.20 / 0.47$ \\
Sample 3 WSE/CTF & $0.14 / 0.10$ & $0.56 / 0.21$ & $0.25 / 0.48$ \\
Sample 4 WSE/CTF & $0.10 / 0.11$ & $0.45 / 0.16$ & $0.22 / 0.69$ \\
Sample 5 WSE/CTF & $0.10 / 0.07$ & $0.54 / 0.22$ & $0.19 / 0.32$ \\
Sample 6 WSE/CTF & $0.07 / 0.02$ & $0.35 / 0.07$ & $0.20 / 0.29$ \\
\hline
\end{tabular}

\subsection{Effects of WSE and CTF solutions on M.a. growth control}

Using both the WSE and CTF solutions, the M.a. growth control tests were conducted similarly to those done using the WSE solution as in Figure 2. The data obtained are shown in Figure 3 when using Sample 1 and in Figure 4 when using Sample 2. Both Sample solutions are almost the same in CT/PP ratio for 
the WSE solutions, but the CT/PP ratios differ a little for the CTF solutions because of the effect of the fractioning treatment. As is shown in Figures 3 and 4, a typical log growth phase of the M.a. cells was observed in the control during the first four days from the starting, while the growth control/inhibition tendency was clearly observed especially for the first six days on occasions of adding the WSE or CTF solution with the initial CTLI level of 13 to $16 \mathrm{pg}-\mathrm{CT} / \mathrm{cell}$. This would be mainly due to the effect of the CT of the organic substances contained in the dead leaves. Considering along with the results in Figure 2, it is assumed that the very effective growth control/inhibition would be sustained for at least 6 to 8 days when the initial CTLI per unit M.a. cell were adjusted to higher than 14 pg-CT/cell.

\subsection{Effects of WSE-R solution on M.a. growth control}

The results in Figures 3 and 4 show that the CTF solution also keeps a good growth control effect on the M.a. cells. Assuming that the growth control effect is due to other factor than the condensed tannin, no growth control effect would be observed when using the WSE-R solution since it presumably contains no or less condensed tannin substance. Therefore, if a growth control effect takes place when using WSE-R solution, there would be other factors affecting the growth control. As for the WSE, CTF and WSE-R solutions for the growth control tests,
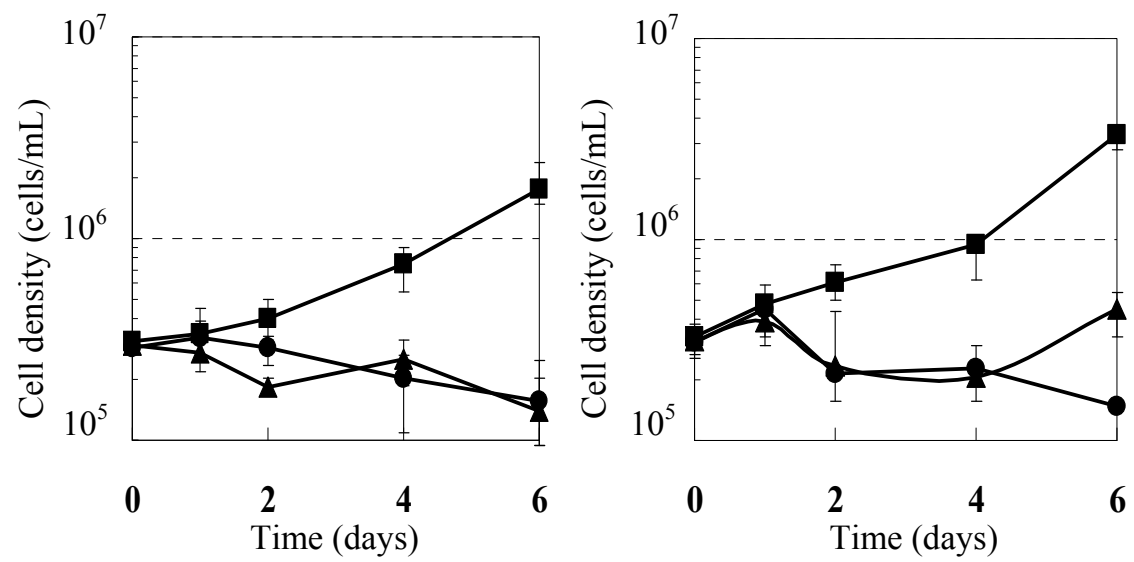

Legends:

a:Control $\boldsymbol{\Delta}$ :WSE(14pg-CT/cell)

Legends:

-:CTF(13 pg-CT/cell)

ш:Control $\boldsymbol{\Delta}: \mathrm{WSE}(16 \mathrm{pg}-\mathrm{CT} /$ cell $)$

$\bullet: \mathrm{CTF}(15 \mathrm{pg}-\mathrm{CT} / \mathrm{cell})$

Figure 3: Effects of WSE and CTF solutions on M.a. growth control at various CTLIs in cases using Sample 1.

Figure 4: Effects of WSE and CTF solutions on M.a. growth control at various CTLIs in cases using Sample 2. 
the CT concentrations and the initial CTLIs are given in Table 4. By the WSE fractioning treatment, the CT concentration in the WSE-R solution decreased down to about $14 \%$ of the original WSE solution. In this case, the rate of the CT recovery from the WSE solution to the CTF plus WSE-R solutions was about $86 \%$.

Table 4: CT concentrations and CTLIs in WSE, CTF and WSE-R solutions.

\begin{tabular}{|c|c|c|}
\hline Solution & $\mathrm{CT} \quad(\mathrm{mg}-\mathrm{CT} / \mathrm{mL})$ & CTLI (pg-CT/cell) \\
\hline WSE & 0.14 & 18 \\
\hline $\mathrm{CTF}$ & 0.10 & 13 \\
\hline WSE-R & 0.02 & 2.2 \\
\hline
\end{tabular}

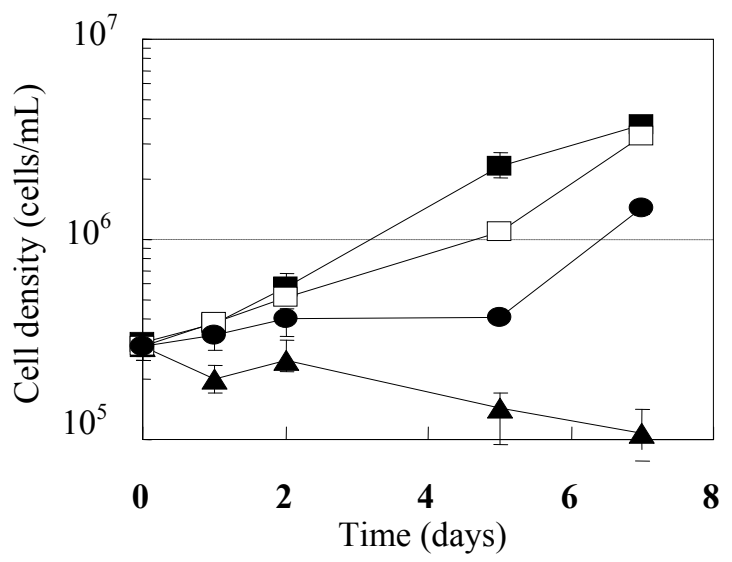

$\begin{array}{ll}\text { Legends: } & \text { Control } \Delta \mathrm{WSE}(18 \mathrm{pg}-\mathrm{CT} / \text { cell }) \\ & -\mathrm{CTF}(13 \mathrm{pg}-\mathrm{CT} / \mathrm{cell}) \quad \text { aWSE-R(2.2pg-CT/cell) }\end{array}$

Figure 5: Effects of WSE, CTF and WSE-R solutions on M.a. growth control.

In Figure 5, the results are shown about the growth control/inhibition tests using the WSE, CTF and WSE-R solutions. The amount of each solution added was $4 \mathrm{~mL}$, and thus the initial CTLI in each solution was $18 \mathrm{pg}-\mathrm{CT} / \mathrm{cell}$ for the WSE solution, $13 \mathrm{pg}-\mathrm{CT} / \mathrm{cell}$ for the $\mathrm{CTF}$ solution and $2.2 \mathrm{pg}-\mathrm{CT} /$ cell for the WSE-R solution. As is shown, the growth control/inhibition effect due to the solution addition seems to be very clearly affected by the initial CTLI level, while there was no clear growth control effect observed when using the WSE-R solution. Therefore, it is assumed that the condensed tannin would function as a growth control factor to the M.a. cells. 


\section{Conclusions}

Widely in temperate zones or cold district regions, the dead leaves of deciduous trees like cherry and maple contain organic substances like polyphenol and especially condensed tannin, and the condensed tannin can easily elute into water. Growth control tests have been conducted to evaluate the effect of the condensed tannin on toxic M.a. cells by using WSE solutions obtained from dead cherry tree leaves. The results above imply that the condensed tannin extracted from the dead leaves of the deciduous trees functions to be very effective for the growth control/inhibition of M.a. cells. A counter measure using the dead leaves would be very rational and effective for the growth control of the toxic cyanobacteria. Some important conclusions are summarized as follows.

1) The CT amount extracted from the dead leaves of cherry trees after seven days immersion at room temperature was 12.7 to $20 \mathrm{mg}-\mathrm{CT} / \mathrm{g}$ for D.I. water, and the possible amount of the CT extracted by a $50 \%$ ethanol solution (ethanol:D.I. water $=1: 1 \mathrm{v} / \mathrm{v}$ ) was 18.6 to $21.9 \mathrm{mg}-\mathrm{CT} / \mathrm{g}$. Accordingly, the CT extraction rate by D.I. water was $0.60 \sim 0.91$ (average 0.72 ) when compared with that by a $50 \%$ ethanol solution.

2) The M.a. cells seem to be growing during the first 8 days of the test period, while the distinct growth control/inhibition was observed in the WSE added-test bottles. This apparently implies that some water soluble substances like condensed tannin would very effectively act for the growth control of the M.a. cells

3) The growth control/inhibition tendency was clearly observed on occasions of the WSE or CTF addition at the CTLI at 13 to $16 \mathrm{pg}-\mathrm{CT} /$ cell especially for the first 6 days. This would be mainly due to the effect of the CT of the organic substances contained in the dead leaves to function as the growth control/inhibition factor.

4) There was no growth control effect observed when using the WSE-R solution with its initial CTLI at $2.2 \mathrm{pg}-\mathrm{CT} / \mathrm{cell}$.

The condensed tannin extracted from the dead leaves could be a major growth control factor on M.a. although the mechanism has not been proven definitely in regards to the growth control of the M.a cell. Our research has been focusing on disclosing the possible mechanism such that the condensed tannin affects on the photosynthesis light reaction activity of the M.a. cells to decrease their energy production function $[18,19]$. As described above, the counter measure against the growth control of Microcystis using the dead leaves of natural plants is supposed to be very effective and rational.
Abbreviations:
CT: Condensed Tannin
CTF: Condensed Tannin Fraction
D.I. water: deionized water
M.a.: Microcystis aeruginosa
PP: Polyphenol 
WSE: Water Soluble Extract

WSE-R: Water Soluble Extract remaining

\section{Acknowledgements}

The present research work has been performed by many students of the Nihon University, College of Science and Technology, Civil Engineering Department Aqua-Enviro System Laboratory. The authors would like to express their sincere gratitude to all students who have contributed to the project over the last three years.

\section{References}

[1] Guangming Z., Panyue Z., Hong L., \& Bo W., Ultrasonic damages on cyanobacterial photosynthesis. Ultrasonic Sonochemistry, 13, pp.501-505. 2006

[2] Yunfeng X., Ji Y., Mingming O., Yalin W., \& Jinping J., Study of Microcystis aeruginosa inhibition by electrochemical method, Biochemical Engineering Journal, 36 (3), pp.215-220, 2007

[3] Ferrier M.D., Butler B.R. Sr., Terlizzi D.E., \& Lacouture R.V., The effects of barley straw (Hordeum vulgare) on the growth of freshwater algae. Bioresource Technology, 96, pp.1788-1795, 2005

[4] Gibson M. T., Welch I. M., Barrett P. R. F, \& Ridge I., Barley straw as an inhibitor of algal growth II: laboratory studies. Journal of Applied Phycology, 2, pp.241-248, 1990

[5] Ridge I., Walters J., \& Street M., Algal growth control by terrestrial leaf litter: a realistic tool?. Hydrobiologia, 395/396, pp.173-180, 1999

[6] Nakai S., Inoue Y., Hosomi M, \& Murakami A., Myriophyllum spicatumreleased allelopathic polyphenols inhibiting growth of blue-green algae Microcystis aeruginosa. Water Research, 34 (11), pp.3026-3032, 2000

[7] Nakayama M., Suzuki K., Toda M., Okubo S., Hara Y., \& Shimamura T., Inhibition of the infectivity of influenza virus by tea polyphenols. Antiviral Research, 21, pp.289-299, 1993

[8] Sakanaka S., Sato T., Kim M., \& Yamamoto T., Inhibitory effects of green tea polyphenols on glucan synthesis and cellular adherence of cariogenic streptococci. Agric. Biol. Chem, 54 (2), pp.2925-2929,1990

[9] Junli Z., Takahashi K., Kono Y., Suzuki Y., Takeuchi S., Shimizu T., Yamaguchi I., Chijimatsu M., Sakurai A., Sato Y., \& Kitamura H., Bioactive condensed tannins from bark; chemical properties, enzyme inhibition and anti-plant viral activities, J. Pesticide Sci., 15, pp.585591,1990

[10] Hattori M., Kusumoto I., Namba T., Ishigami T., \& Hara Y., Effect of tea polyphenols on glucan synthesis by glucosyltrans ferase from Streptococcus mutans. Chem. Pharm, Bull. 38 (3), pp.717-720, 1990 
[11] Ikigai H., Nakae T., Hara Y., \& Shimamura T., Bactericidal catechins damage the lipid bilayer. Biochimica Biophysica Acta, 1147, pp.132-136, 1993

[12] Toda M., Okubo S., Ikigai H., Suzuki T., Suzuki Y., \& Shimamura T., The protective activity of tea against infection by vibrio cholerae 01 . Journal of Applied Bacteriology, 70, pp.109-112, 1991

[13] Augustin S., Antimicrobial properties of tannins. Phytochemistry, 30 (12), pp.3875-3883,1991

[14] Kitamura N., Nagakawa T., Yoshida Y., Matsushima H., \& Asada Y., Studies on the growth control of toxic Cyanobacteria by use of the waterextracts from the dead leaves of deciduous trees. Environmental Engineering Research, JSCE, 43, pp.543-549, (in Japanese) 2006

[15] Tanno K. \& Nonomura H., Antibacterial substances in green tea extract. Japanese Society for Food Sci. and Tech. 21 (9), pp.445-449. (in Japanese) 1974

[16] Richard B. B. \& William T. J, Analysis of condensed tannin using acidified vanillin. J. of the Science of Food and Agriculture, 29, pp.788-794, 1978

[17] Folin O. \& Denis W., On phosphotungstic-phosphomolybdic compounds as color reagents. J. Biol. Chem. 12, pp.239-243,1912

[18] Shimada K., Kitamura N., Nomoto S., Yoshida Y., Matsushima H., \& Asada Y., Effect of the condensed tannin from the dead leaves of deciduous trees on the photosynthesis reaction inhibition to Microcystis aeruginosa. Proc. of EMECS 8th Conf. pp. 132-133, 2008

[19] Shimada K., Nomoto S., Kitamura N., Yoshida Y., Matsushima H., \& Asada Y., Mechanism of growth control of toxic cyanobacteria by use of the dead leaves of roadside trees. The $3^{\text {rd }}$ ASPIRE-IWA Conference and Exhibition. oral-STD8-0-2, 2009 